\title{
LA PERCEPCIÓN DEL RIESGO VOLCÁNICO POR LA ACTIVIDAD DEL TURRIALBA (2010-2017) EN LAS COMUNIDADES DE LA PASTORA Y EL TAPOJO, COSTA RICA
}

\author{
THE PERCEPTION OF THE VOLCANIC RISK FOR THE TURRIALBA ACTIVITY (2010-2017) IN THE \\ COMMUNITIES PASTORA AND TAPOJO, COSTA RICA
}

\author{
Daniela Campos-Durán ${ }^{1}$, Guillermo E. Alvarado² \\ 1 Universidad Nacional de Costa Rica (UNA), Heredia, Costa Rica \\ ${ }^{2}$ Comisión Nacional de Prevención de Riesgos y Atención de Emergencias (CNE), San José, Costa Rica
}

Correspondência para: Daniela Campos Durán (daniela.campos.duran@una.cr)

doi: 10.12957/geouerj.2019.44819

Recebido em: 27 ago. 2019 | Aceito em: 17 set. 2019

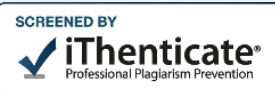

\section{RESUMEN}

El 5 de enero de 2010, el volcán Turrialba inició su periodo eruptivo asociado a la caída de ceniza, actividad que se mantiene hasta el presente (mayo de 2019), destacando las erupciones del 29 de octubre de 2014, del 12 de marzo de 2015 y del 19 de setiembre de 2016, que afectaron las actividades productivas de las comunidades localizadas en el flanco sur del volcán, en los sectores pecuario (producción de leche y queso) y agrícola (cultivo de papa, repollo, cebolla y zanahoria), por lo que presentaron condiciones de vulnerabilidad ante la actividad volcánica con pérdidas económicas entre el 2010 y el 2017. El presente artículo analiza la percepción de la población de La Pastora y El Tapojo en relación con los peligros volcánicos asociados al Turrialba y su nivel de vulnerabilidad. Para ello, se realizaron grupos focales con líderes comunales con el objetivo de conocer su percepción sobre las condiciones de riesgo, lo cual se contrastó con información científica existente sobre los peligros volcánicos. El análisis demostró que existe una importante coincidencia entre los datos científicos de los peligros volcánicas del Turrialba y la percepción de la población, ya que señalan que la caída de ceniza, los gases, la sismicidad, la lluvia ácida y los lahares representan una amenaza para elementos que podrían verse afectados en la comunidad, principalmente en las actividades agropecuarias, viviendas y puentes.

Palabras-clave: Percepción del riesgo, peligros volcánicos, volcán Turrialba, Costa Rica.

\begin{abstract}
On January $5^{\text {th }}, 2010$, Turrialba volcano began its eruptive period, associated with ash fall, activity which has kept until now (May 2019), highlighting the eruptions on October 29, 2014, March 12, 2015 and September 19, 2016, which affected the production activities of communities located on the South Flank of the volcano, in the livestock (milk and cheese production) and agricultural (cultivation of potato, cabbage, onion and carrot) sectors, show vulnerability conditions to volcanic activity with economic losses between 2010 and 2017. The present article analyzes the perception of population in Pastora and Tapojo in relation with the volcanic hazards associated with Turrialba volcano and its vulnerability level. For it, some focus groups were created with community leaders that have the target of knowing its perception about the risk conditions, which contrasted with existing scientific information about the volcanic hazard. This analysis showed that there exists an important coincidence between scientific data of volcanic threats of Turrialba and perception of population, since they point out that ash fall, gases, seismicity, acid rain and lahares, represented a threat for elements that could be affected in the community, mainly the agricultural activities, housing and bridges.
\end{abstract}

Keywords: Perception of the risk, volcanic hazards, Turrialba volcano, Costa Rica.

\section{INTRODUCCIÓN}


El volcán Turrialba se localiza en la provincia de Cartago, $16 \mathrm{~km}$ al noroeste de la ciudad de Turrialba y posee una altura de 3340 metros sobre el nivel del mar (Figura 1). A partir de 1996 se empezaron a registrar enjambres sísmicos asociados a la actividad superficial alineada a lo largo de las grandes estructuras tectónicas y a leves cambios en la desgasificación (Hilton et al 2010; Duarte, 2015). En el 2005, el Turrialba inició una nueva etapa de actividad asociada a aumentos en la temperatura, para el 2007, se dio un aumento en la acidificación de las fumarolas y en los enjambres sísmicos; para este año las principales afectaciones fueron en pastizales, algunos cultivos e infraestructura de La Picada y Finca Silvia (Abarca y Alvarado, 2017).

En enero de 2010, se dio la primera erupción de ceniza, por lo que el Ministerio de Agricultura y Ganadería (2010) señaló que la mayor proporción de las explotaciones pecuarias con afectación se encontraban en el distrito de Santa Cruz de Turrialba. Sin embargo, entre el 2014 y el 2016, se registraron las erupciones más intensas, con columnas eruptivas desde los 500 hasta los $4000 \mathrm{~m}$ de altura (Alvarado et al., 2016; Campos y Alvarado, 2018). Esta actividad tuvo como consecuencia afectación directa en el sector agropecuario principalmente en los cantones de Alvarado, Oreamuno y Turrialba, en el caso de este último también se dio emigración de la población, esto en los caseríos La Silvia (en los mapas oficiales del Instituto Geográfico Nacional señalada como finca Retiro, aunque la población se refiere a La Silvia), La Picada y La Central (en los mapas oficiales del Instituto Geográfico Nacional señalada como Finca Central), así como población evacuada durante las erupciones de 2014. La actividad del Turrialba tuvo su clímax entre finales del 2014 hasta el 2016; a partir del 2017 hasta el presente (Alvarado et al., 2016; Campos y Alvarado, 2018), la actividad eruptiva comenzó a decrecer, presentando hasta mayo del 2019, erupciones de ceniza de poca monta. 


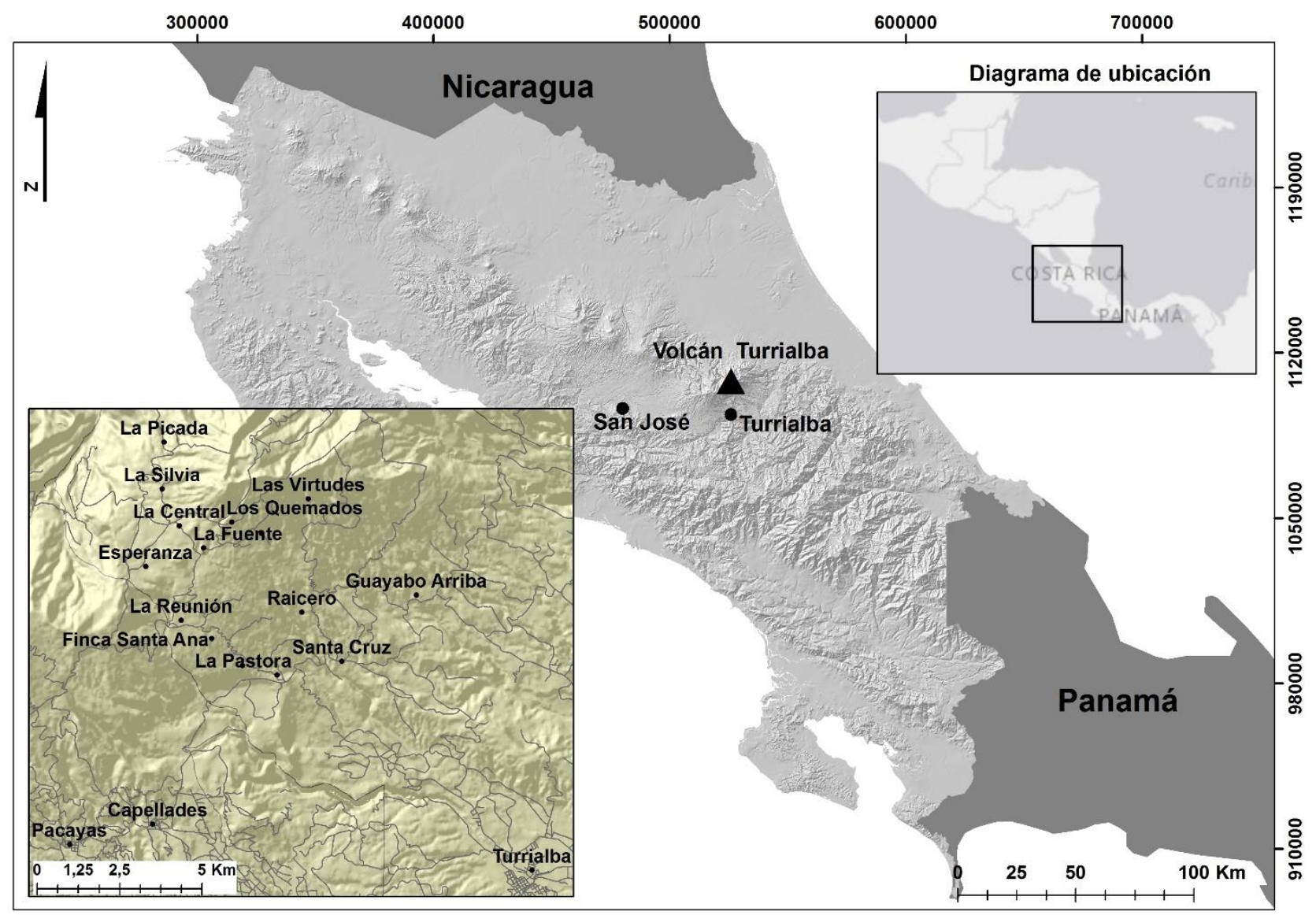

Figura 1. Ubicación del volcán Turrialba y principales comunidades y poblados afectados. Fuente: Elaboración propia a partir del Hojas topográficas Bonilla, Tucurrique e Istarú (Escala 1:50 000) y trabajo de campo.

Para octubre de 2014, debido a la magnitud de las erupciones, la Comisión Nacional para la Prevención de Riesgos y Atención de Emergencias (CNE) declaró alerta amarilla en Turrialba por la caída de ceniza y gases, donde 11 personas fueron evacuadas y trasladadas a un albergue temporal en el salón comunal de Santa Cruz. Además, se dio el cierre indefinido de 13 centros educativos en los cantones de Alvarado, Oreamuno y Turrialba; en este último se vieron afectados los estudiantes de poblados como La Central, La Picada y El Tapojo, localizados en el distrito de Santa Cruz (Arguedas, 2014). Para marzo de 2015, debido a las erupciones de ceniza y gases, la CNE ordenó el cierre de las vías de acceso en los sectores de La Pastora, La Central y Las Virtudes de Turrialba.

Por lo tanto, esta investigación plantea conocer la percepción de la población de La Pastora y El Tapojo ante los peligros volcánicos, ya que son las comunidades más cercanas al volcán que aún se encuentran habitadas y donde se han dado mayores afectaciones en el sector agropecuario, principal actividad económica en el área de estudio. Así como analizar cuál es la percepción que la población tiene sobre los 
peligros volcánicos, factor que puede facilitar los procesos de gestión de riesgos, principalmente los enfocados en la temática de prevención y preparativos de respuesta, así como a la generación de lineamientos para los planes comunales de emergencias.

\section{MÉTODOS Y TÉCNICAS}

Esta investigación se llevó a cabo a través de la aplicación de la técnica de grupo focal que corresponde a una entrevista grupal que utiliza la comunicación entre el investigador y los participantes, con el propósito de obtener información, donde participan entre tres y 10 personas (Hamui y Varela, 2013). El grupo focal, con el que se trabajó, estuvo conformado por actores claves de las comunidades La Pastora y El Tapojo, destacando integrantes del Comité Comunal de Emergencias de La Pastora, miembros de la Asociación de Desarrollo Integral de La Pastora, de la Asociación Administradora de Acueductos Rurales (ASADA) de La Pastora. La actividad tuvo como finalidad conocer la percepción de población a través del desarrollo de cartografía participativa, donde la población identificó de acuerdo con su percepción los peligros a los que se sentían expuestos, su distribución espacial y los elementos expuestos a daños, obteniendo así un mapa comunitario de percepción de riesgo.

Los riesgos que se contemplaron en la elaboración del mapa comunitario se catalogaron de acuerdo con la clasificación de peligros volcánicos planteada por Tilling (1989), correspondientes a caída de ceniza, lluvia ácida, gases, flujos de lodo (lahares), sismos, deslizamientos, coladas de lava y flujos piroclásticos. Una vez elaborado el mapa comunitario de percepción de riesgos, la población participante elaboró un análisis grupal para de los riesgos identificados, el cual contempló cinco variables: riesgo, impacto esperado, medidas de prevención o mitigación y actores responsables; asimismo, se estableció un valor de importancia para cada riesgo, el cual correspondió a alto, medio y bajo según la percepción de los participantes. Posterior a ello, la información contenida en el mapa comunitario de percepción de riesgos, elaborado por el grupo focal, se integró en un SIG (Arc Gis 10.1) para su análisis. Además, se llevó a cabo trabajo de campo para identificar y caracterizar los riesgos señalados por la población, información que se contrastó con datos científicos, tal como el estudio elaborado por Soto (2012), así como la 
modelación de lahares elaborado por Ruiz et al. (2015) e informes técnicos del OVSICORI-UNA y la RSN: UCR-ICE sobre la dispersión de gases y actividad sísmica en el área de estudio, entre otros.

\section{RESULTADOS Y DISCUSIÓN}

\section{Percepción por caída de ceniza}

Para el riego por caída de ceniza, el grupo focal manifestó que existen elementos expuestos, como los cultivos (papa, repollo, cebolla y zanahoria), el pasto, el ganado, las viviendas y la población. Las actividades pecuarias y agrícolas, que se desarrollan alrededor del volcán, en sectores como las haciendas La Central, La Fuente, La Reunión y la lechería El Tapojo, fueron señalados como los más vulnerables ante la caída de ceniza. Incluso, esta percepción se ve reforzada debido a que, en los últimos años, el área de estudio ha sido afectada por caída de ceniza, principalmente desde el 2010, cuando el volcán inicio su actividad, la cual se sostuvo de manera intensa hasta 2017, lo que generó pérdidas económicas en el sector agropecuario y, por ende, procesos de emigración en las fincas más cercanas al volcán (Figura 2).
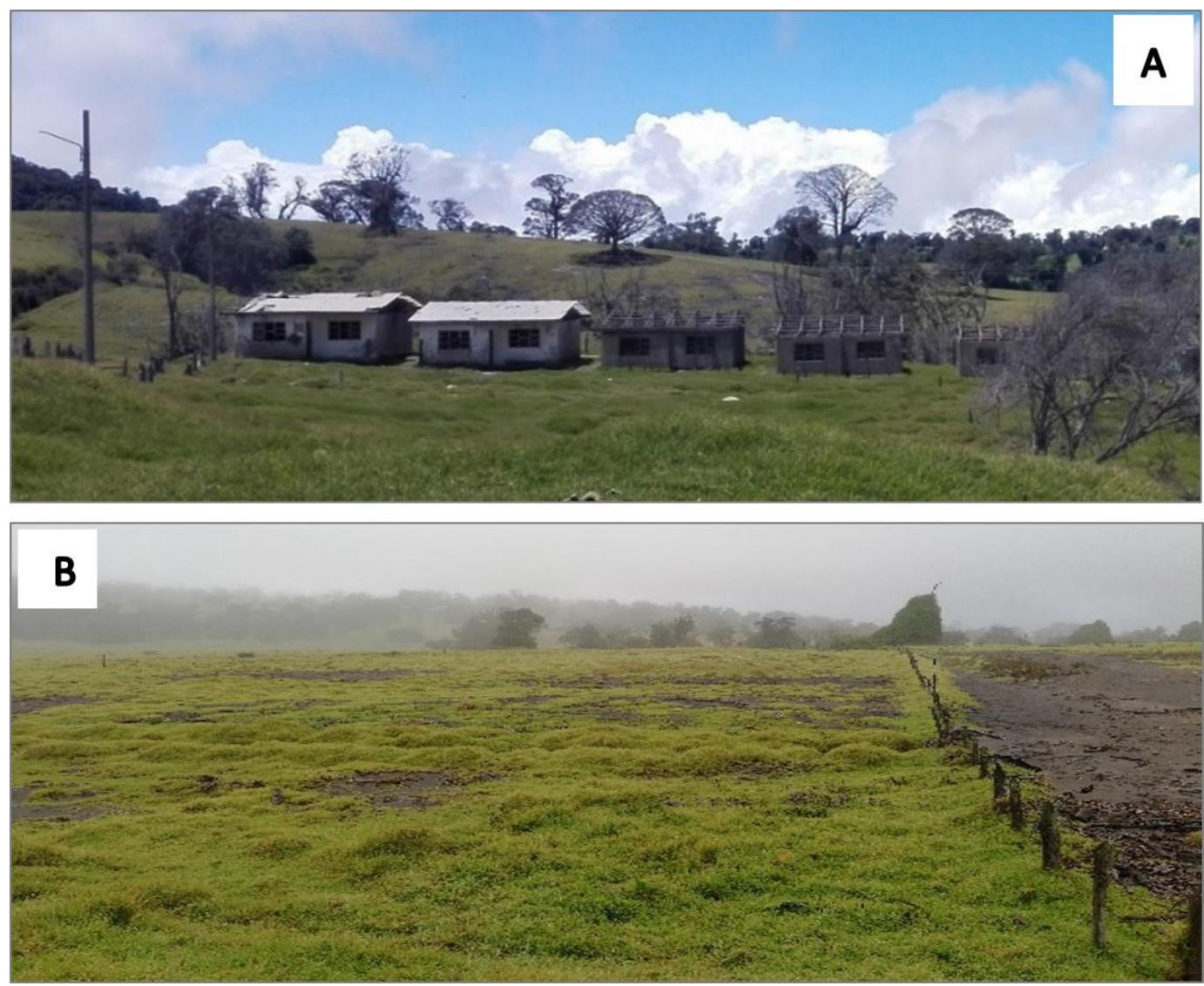

Figura 2. A). Viviendas con notables daños en el sector de la finca La Silvia (en los mapas del Instituto Geográfico Nacional señalada como El Retiro, aunque la población local lo conoce como La Silvia), sitio que se encuentra deshabitado. B). Pastos afectados por la ceniza en el sector de finca La Central. Fuente: Propia, 2017. 
Los mayores efectos se dieron durante las erupciones del 29 de octubre al $1^{\circ}$ de noviembre del 2014 debido a la dirección de los vientos hacia el sureste. De acuerdo con la Agencia de Extensión Agropecuaria de Turrialba (2014), se vieron afectados en este sector 106,5 hectáreas de cultivos (papa, repollo, zanahoria, cebolla y brócoli), 84 fincas ganaderas, en las que se contabilizaron 3559 cabezas de ganado y 84 productores. La población indicó que la cantidad de ceniza sobre los techos era considerable, además las partículas de ceniza entraban fácilmente a las viviendas, siendo esta la erupción que los pobladores de La Pastora y El Tapojo recuerdan como la que mayor afectación generó. En el 2015, las erupciones del 16 al 31 de octubre afectaron 5,4 hectáreas de cultivos (papa y repollo) y se evacuaron 29 animales que estaban presentando, problemas respiratorios debido a la inhalación de gases y cenizas. En el 2016 las erupciones del 13 y 14 de octubre afectaron cultivos y pastos en las haciendas y poblados de La Central, La Fuente, La Reunión, La Pastora, La Palmira, Las Virtudes, El Tapojo y El Triunfo. Durante el 2 y 3 de octubre de 2017, las erupciones tuvieron afectaciones muy puntales en una finca dedicada al cultivo de repollo en La Pastora y tres fincas ganaderas localizadas en El Tapojo (Agencia de Extensión Agropecuaria de Turrialba, 2017).

De acuerdo con la población, el mes de octubre está considerado como el más crítico para las comunidades en caso de se presenten futuras erupciones con caída de ceniza. Lo anterior concuerda con lo expuesto por Campos y Alvarado (2018), quienes señalan que entre el 2010 y el 2018 se generaron un total de 32 reportes por caída de ceniza, cinco en La Central, 14 en La Pastora y 13 en El Tapojo. Sumado a ello, el estudio de Soto (2012), sobre los escenarios por caída de ceniza, muestra que ambas comunidades se encuentran dentro del área de afectación bajo tres escenarios posibles (Tabla 1).

\begin{tabular}{ccc}
\hline Escenario & Espesor en $\mathbf{~ e m}$ & Comunidades afectadas \\
\hline Erupción Vulcaniana (febrero) & $2-30$ & La Pastora \\
& $30-100$ & El Tapojo \\
Erupción Pliniana (febrero) & $30-100$ & La Pastora \\
& $100-300$ & El Tapojo \\
Erupción Pliniana (mayo) & $0,1-2$ & La Pastora \\
& $30-100$ & El Tapojo \\
\hline
\end{tabular}

Tabla 1. Espesor en centímetros por caída de ceniza en las comunidades La Pastora y El Tapojo según escenarios de Soto (2012). Fuente: Soto (2012). 
Ante dichos escenarios, Soto (2012) señala que las erupciones futuras, en el orden de años o décadas, representan una amenaza muy importante a las fincas y viviendas en los alrededores del volcán. Para ello, las erupciones vulcanianas deberían considerarse en un escenario de corto plazo, donde las áreas más afectadas serían los 10 km periféricos alrededor del volcán y la falda sur del volcán Irazú hasta la periferia de Cartago.

La figura 3 muestra que el área delimitada por el grupo focal, por caída de ceniza, concuerda con lo establecido en los escenarios de las erupciones vulcaniana y pliniana (esta última poco probable al presente), donde ambas comunidades se verían afectadas. Para el caso de las erupciones vulcanianas, Alvarado et al. (2016) señalan que este tipo de erupciones, se dieron entre el 2014 y el 2016 y presentaron fases muy activas de varios días y hasta semanas (entre 14 y 71 días), con lapsos prolongados de tranquilidad (semanas a varios meses). A finales del 2014 las erupciones presentaron un Índice de Explosividad Volcánica (VEI) entre 0 y 2, las cuales siguieron con altibajos a lo largo de todo el 2015 e incluso gran parte del 2016.

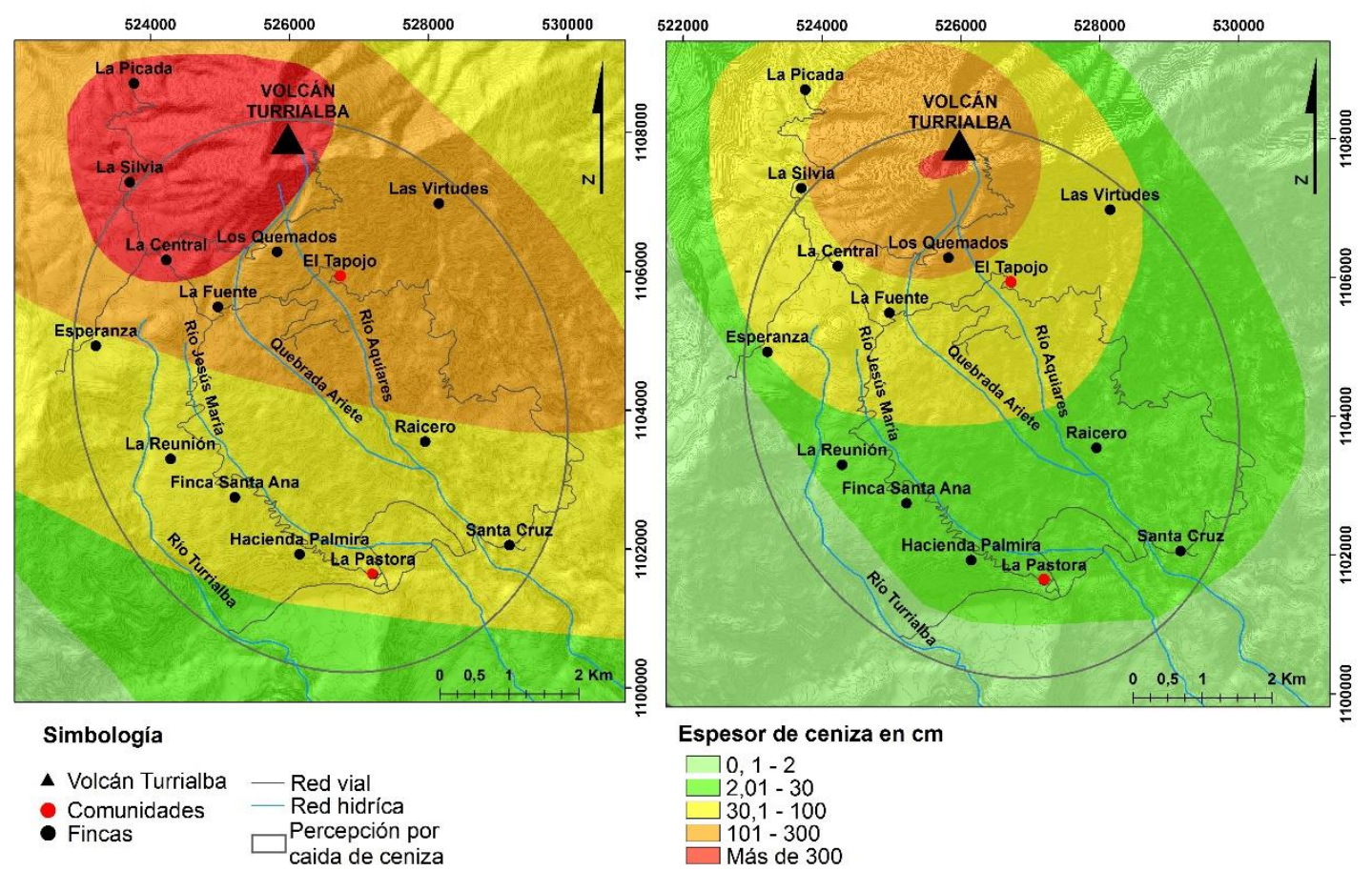

Figura 3. A). Distribución y espesor de cenizas para erupción pliniana esperada en febrero, donde se proyecta un espesor entre 30 - $100 \mathrm{~cm}$ en El Tapojo y 2 - $30 \mathrm{~cm}$ en La Pastora. B). Distribución y espesor de cenizas para erupción vulcaniana esperada en febrero donde se proyecta un espesor entre 30 - $100 \mathrm{~cm}$ en El Tapojo y 2 - $300 \mathrm{~cm}$ en La Pastora. C). En ambas figuras se observa la delimitación que hicieron los participantes del grupo focal del área que ellos perciben como de riesgo por caída de ceniza, lo cual coincide con los escenarios elaborados por Soto (2012). Fuente: Elaboración propia a partir de Soto (2012), trabajo del grupo focal y trabajo de campo. 
Resulta importante hacer hincapié en que mientras el grupo focal manifestó que perciben un mayor riesgo por caída de ceniza durante octubre, debido a la dirección de los vientos. Sin embargo, los escenarios realizados por Soto (2012) no contemplan este mes dentro de sus modelaciones, por lo que sería interesante que futuras investigaciones lo integren dentro de sus escenarios, ya que erupciones recientes como la del 30 de octubre de 2014 generaron importantes pérdidas agropecuarias en el área de estudio. La Tabla 2 muestra un resumen comparativo entre la percepción del grupo focal y la información científica generada sobre los escenarios de distribución y espesor por caída de ceniza en el área de estudio.

\begin{tabular}{|c|c|c|}
\hline Percepción del grupo focal & Información científica & Análisis comparativo \\
\hline $\begin{array}{l}\text { La población participante } \\
\text { identificó espacialmente las áreas } \\
\text { de caída de ceniza y señalaron, } \\
\text { además, elementos vulnerables, tal } \\
\text { como las actividades } \\
\text { agropecuarias y viviendas, lo que } \\
\text { conllevó a que perciban como alto } \\
\text { el riesgo por caída de ceniza, } \\
\text { principalmente durante octubre, } \\
\text { cuando los vientos van en dirección } \\
\text { sureste. }\end{array}$ & $\begin{array}{l}\text { De acuerdo con el estudio de Soto } \\
\text { (2012), existen tres escenarios de } \\
\text { distribución y caída de ceniza que } \\
\text { puede afectar el área de estudio. } \\
\text { Este mismo autor señala que las } \\
\text { erupciones futuras, representan una } \\
\text { amenaza muy importante a las } \\
\text { fincas y viviendas en los alrededores } \\
\text { del volcán, tal como lo es el caso de } \\
\text { La Pastora y El Tapojo. }\end{array}$ & $\begin{array}{l}\text { La población tiene una percepción } \\
\text { que se corresponde con el potencial } \\
\text { de caída de ceniza, la cual coincide } \\
\text { con lo establecido en los estudios } \\
\text { realizados por Soto (2012). } \\
\text { Además, ellos identificaron } \\
\text { elementos expuestos a ser afectados } \\
\text { por caída de ceniza, principalmente } \\
\text { las actividades agropecuarias y } \\
\text { viviendas. }\end{array}$ \\
\hline
\end{tabular}

Tabla 2. Resumen comparativo entre la percepción del grupo focal y la información científica sobre la caída de ceniza. Fuente: Propia, a partir de grupo focal (2017) y Soto (2012).

\section{Percepción por gases}

El volcán Turrialba ha mantenido en los últimos años una actividad de desgasificación que ha tenido efectos sobre la vegetación e infraestructuras de las comunidades aledañas. Entre las sustancias que conforman esta actividad de desgasificación se encuentra el dióxido de carbono y el dióxido de azufre, que se han ido incrementando y son capaces de afectar la salud respiratoria de quienes se exponen a ellas (Yglesias y Chamizo, 2014). En este sentido, datos del OVSICORI-UNA señalan que el nivel de $\mathrm{CO}_{2}$ se ha incrementado en aproximadamente un $90 \%$ (Martini, 2009), ya que las emisiones pasaron de 1 ton/día en el 2002 a 740 ton/día en enero de 2008 (Martini et al., 2008). 
La actividad de desgasificación, aunque es un evento de baja peligrosidad, tal como lo señala Soto (2012), si esta prevalece por largos periodos de tiempo, puede tener efectos negativos no solo sobre la vegetación, los animales y los cultivos, sino que, además, puede afectar la salud de la población que se encuentra expuesta. En efecto, este incremento de gases coincide con la percepción de los participantes del grupo focal, quienes lo señalaron como un riesgo alto, ya que manifestaron que la presencia de los gases, además del fuerte olor, ha ocasionado en ellos y otros habitantes de la comunidad problemas respiratorios.

El estudio realizado por Yglesias y Chamizo (2014), respalda dicha percepción, ya que según su investigación, acerca de la susceptibilidad y síntomas respiratorios asociados a la exposición a dióxido de carbono y dióxido de azufre en ocho comunidades ubicadas en las faldas del Turrialba (fincas La Silvia, La Central, El Retiro, La Fuente, La Esperanza, Las Virtudes y Guayabo Arriba), se determinó que los niños y adultos mayores son los grupos poblacionales que más sintomatología han presentado asociada a molestias en la garganta. Por tanto, estos grupos son los que presentan mayor riesgo de desarrollar síntomas y problemas respiratorios. A nivel general, es importante resaltar que estudios como el realizado por Yglesias y Chamizo (2014), demuestran que un incremento en los gases volcánicos, principalmente dióxido de carbono y dióxido de azufre, han generado problemas en la salud de la población cercana al coloso.

Lo anterior coincide con lo manifestado por el grupo focal, ya que La Pastora y El Tapojo, ubicadas a 2 y $6 \mathrm{~km}$ al sureste del coloso, respectivamente, por su cercanía al Turrialba, presentan un importante nivel de exposición, principalmente niños y adultos mayores, los cuales son los grupos poblacionales más vulnerables (Tabla 3 ). 


\begin{tabular}{|llllr|}
\hline \multicolumn{2}{|c}{ Percepción del grupo focal } & \multicolumn{1}{c|}{ Información científica } & Análisis comparativo \\
\hline La población señaló que los & Datos científicos del OVSICORI - & La población tiene una aceptable \\
gases volcánicos representan un & UNA, han demostrado que el & percepción del riesgo que \\
riesgo alto para los habitantes & Turrialba ha tenido un aumento & representan los gases para la \\
del área de estudio, ya que en & significativo en el nivel de $\mathrm{CO}_{2}$, lo & salud, lo cual coincide con los \\
estas comunidades se han dado & cual ha impactado de manera & datos científicos tales como los \\
problemas de salud asociados al & directa en la salud de la población, expuestos por Yglesias y Chamizo \\
efecto de los gases, & tal como lo demuestra el estudio & (2013). \\
principalmente en niños y & realizado por Yglesias y Chamizo & \\
adultos mayores. & (2013), donde la población adulta & \\
& mayor e infantil son quienes más & \\
& sintomatologías han presentado. & \\
\hline
\end{tabular}

Tabla 3. Resumen comparativo entre la percepción del grupo focal y la información científica sobre los gases volcánicos .Fuente: Propia, a partir de grupo focal (2017), Yglesias y Chamizo (2013) y OVSICORI - UNA (2009).

\section{Percepción por Iluvia ácida}

Referente al riesgo por lluvia ácida, Soto (2012) señala que desde el 2010, la actividad freática del Turrialba ha estado asociada a la emisión de gases ácidos $\left(\mathrm{SO}_{2}\right.$ y $\mathrm{HCl}$, principalmente), los cuales, con la humedad ambiental y las nubes, han promovido la formación de nubes ácidas y su consecuente precipitación como lluvia ácida $(\mathrm{pH}<5,6)$, lo que ha afectado fuertemente el flanco oeste del volcán, debido a la dirección de los vientos provenientes del Caribe. De acuerdo con la RSN(UCR-ICE) (2013), las áreas de mayor afectación se localizan en los sectores oeste y suroeste y con menor afectación en los sectores suroeste y sureste del volcán, por tanto, La Pastora y El Tapojo se localizan en áreas de afectación por lluvia ácida, donde El Tapojo presentó para el periodo 2007 - 2011 una afectación fuerte, mientras que para el caso de La Pastora la afectación fue leve.

Esta distribución de lluvia ácida coincide en gran medida con lo manifestado por los participantes del grupo focal, quienes señalaron que la mayor afectación se ha dado principalmente al oeste y suroeste del coloso, donde se localizan sectores como, La Picada, La Central y La Silvia, los cuales fueron los sectores más afectados (Figura 4). Según datos de la RSN (UCR-ICE), entre el 2007 y 2011, el pH de estos sectores fue de los más ácidos, ya que los valores registrados estuvieron entre 2,74 y 3,58. 

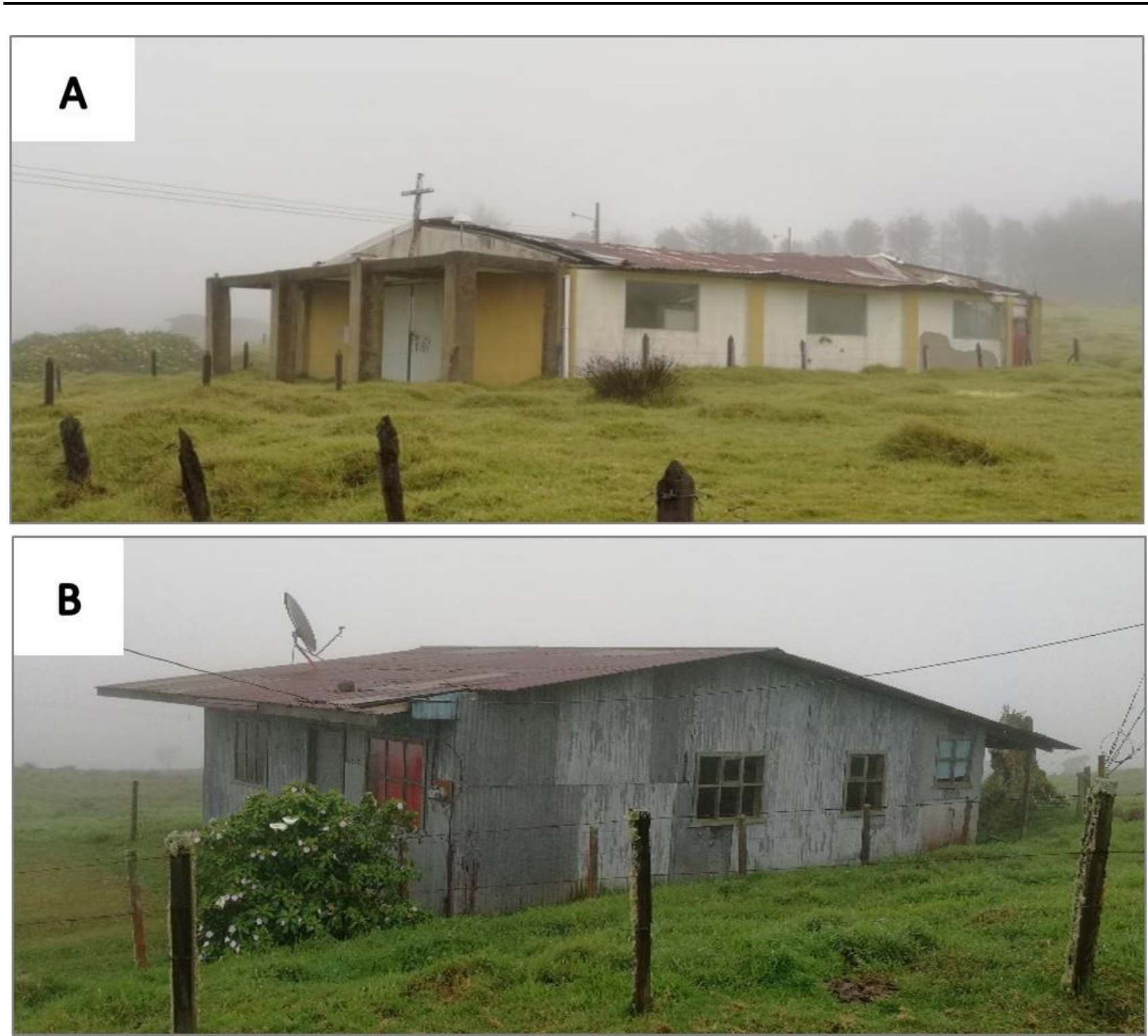

Figura 4. A). Iglesia ubicada en el sector de finca La Central (sector de afectación fuerte por lluvia ácida), la cual presenta signos importantes de corrosión y deterioro asociado a la lluvia ácida y gases. B). Vivienda ubicada entre La Pastora y La Central con notables signos de corrosión en el techo por la lluvia ácida. Fuente: Propia, 2017.

A pesar del impacto que ha tenido la lluvia ácida sobre las estructuras (viviendas y lecherías) y la vegetación, esta fue calificado por los participantes como un riesgo bajo, ya que las fincas localizadas al oeste y suroeste del volcán, tales como La Picada y La Silvia, si bien han presentado en años recientes afectación en los pastos, cultivos, viviendas y lecherías, actualmente son sectores deshabitados, donde se observaron viviendas y lecherías abandonadas que presentan importantes daños asociados a la lluvia ácida, lo que se apreció en la corrosión de las estructuras (Figura 2A).

Caso contrario en La Pastora, El Tapojo y fincas aledañas, donde la población manifestó, según su percepción, que no se han dado afectaciones importantes en los sistemas agropecuarios ni en la 
infraestructura a causa de la lluvia ácida. Por tanto, el área que delimitó el grupo focal por riesgo de lluvia ácida es menor si se compara, por ejemplo, con la caída de ceniza o los gases. Esta percepción fue validada con los datos de la RSN (UCR - ICE) (2013), ya que, para este año, en La Pastora y El Tapojo entre enero y marzo se registró un pH entre 6,89 y 4,73 (Figura 5). A pesar de que estos datos corresponden al 2013, son los únicos datos oficiales con los que se cuenta para validar la percepción por lluvia ácida.

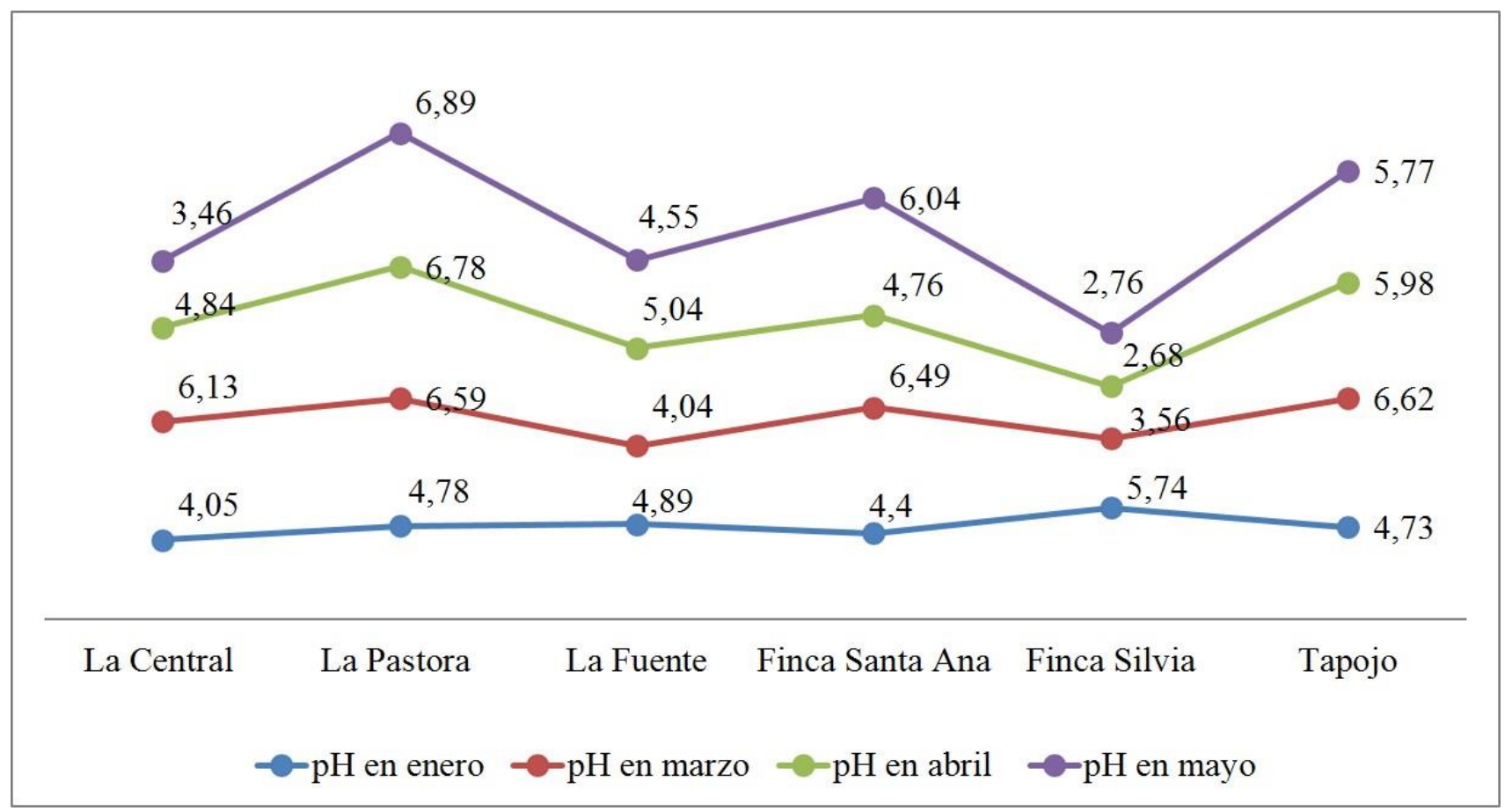

Figura 5. Registros de pH por lluvia ácida en el área de estudio entre enero y mayo de 2013. Fuente estudio de la RSN (UCR - ICE) (2013).

Los datos expuestos en la figura 5 demuestran que el sector donde se localiza La Silvia presentó los niveles más ácidos de $\mathrm{pH}$, los cuales pasaron de 5,74 en enero a 2,76 en mayo; caso contrario en La Pastora donde el pH pasó de 4,78 a 6,89. Si bien la lluvia es considerada ácida cuando los valores de pH son menores a 5,6, cabe resaltar que La Pastora y El Tapojo registraron en mayo valores de pH de 6,89 y 6,77 , respectivamente, lo cual indica que no se dieron condiciones de lluvia ácida; sin embargo, en La Silvia para dicho mes el valor de $\mathrm{pH}$ registrado fue de 2,76. Según estos datos el área de estudio se localiza dentro de una zona de lluvia ácida, donde El Tapojo presenta mayor afectación que La Pastora, por tanto, la percepción de la población coincide en gran medida con los registros de lluvia ácida 
que se exponen en esta investigación, ya que delimitaron de una manera muy precisa las áreas de mayor afectación (Figura 6).

Lo anterior se puede traducir como el hecho de que la lluvia ácida no ha ocasionado daños importantes en La Pastora ni en El Tapojo; por tanto, no fueron áreas delimitadas por la población participante como de posible afectación. Caso contrario, el sector delimitado por el grupo focal, donde los pobladores reconocen que ha sido el área de mayor impacto, lo cual si concuerda con los datos científicos que la definen como un área de afectación fuerte y que ha registrado los valores más bajos de $\mathrm{pH}$, tal como se expuso en la Figura 5.

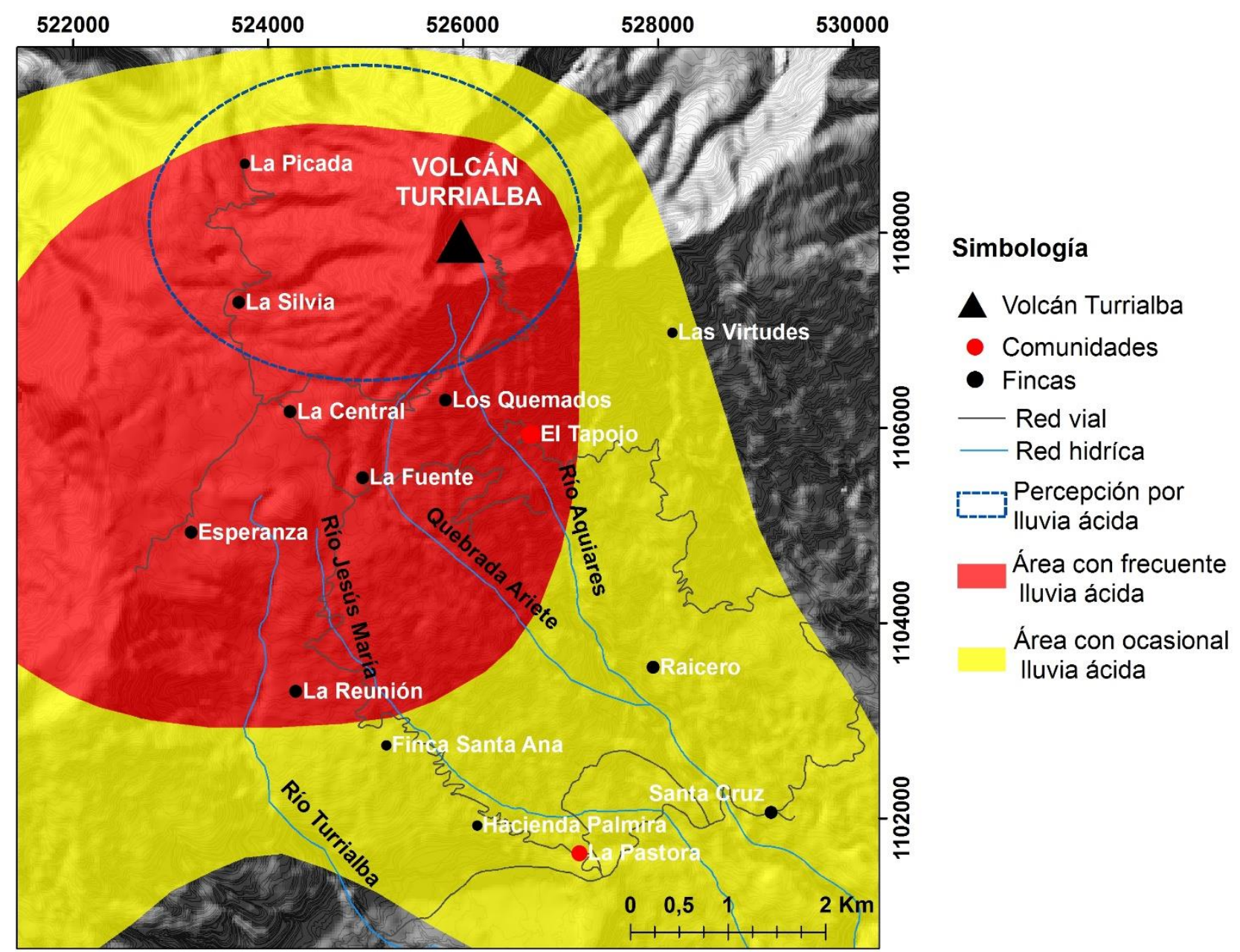

Figura 6. Área de afectación frecuente y ocasional por lluvia ácida, según datos de la RSN (UCR-ICE) para los años 2007 2011, donde La Pastora y El Tapojo presentan afectación leve y fuerte respectivamente. Asimismo, se aprecia el área que la población delimitó como de afectación por lluvia ácida. Fuente: Elaboración propia a partir de RSN (UCR - ICE) (2013), trabajo del grupo focal y trabajo de campo. 
Los datos sobre lluvia ácida demuestran que sectores como las fincas La Central, La Silvia y La Picada presentaron los valores más bajos de $\mathrm{pH}$, lo cual tiene una alta correspondencia con lo indicado por el grupo focal, que, si bien esta población manifestó que no existe afectación en La Pastora y El Tapojo por lluvia ácida, sin embargo, los datos de la RSN (UCR-ICE) los señalan como áreas de afectación leve y fuerte, respectivamente (Tabla 4 ).

\begin{tabular}{|c|c|c|}
\hline blación & Información científica & An \\
\hline $\begin{array}{l}\text { Según la percepción de la } \\
\text { población participante } \\
\text { afectación por lluvia ácida se ha } \\
\text { dado principalmente en fincas al } \\
\text { oeste y suroeste del volcán. } \\
\text { Asimismo, señalaron que las } \\
\text { comunidades La Pastora y El } \\
\text { Tapojo no se han visto afectadas a } \\
\text { causa de la lluvia ácida. }\end{array}$ & $\begin{array}{l}\text { Según datos de la RSN (UCR - } \\
\text { ICE), para el periodo } 2007- \\
2011 \text {, se determinaron dos áreas } \\
\text { de afectación por lluvia ácida, una } \\
\text { de afectación fuerte }\left(33 \mathrm{~km}^{2}\right) \text { y } \\
\text { otra de afectación leve }\left(94 \mathrm{~km}^{2}\right) \text {, } \\
\text { en las cuales se identificó que } \\
\text { existe un impacto directo sobre el } \\
\text { área de estudio. Asimismo, datos } \\
\text { del } 2013 \text { indican elevados niveles } \\
\text { de acidez para sectores como La } \\
\text { Silvia y La Central, caso contrario } \\
\text { La Pastora donde los niveles de } \\
\text { acidez registrados fueron bajos. }\end{array}$ & $\begin{array}{l}\text { La población participante logró } \\
\text { identificar una de las áreas que se } \\
\text { ha visto más afectada por la lluvia } \\
\text { ácida (Finca Silvia, La Picada y } \\
\text { Finca Central), lo que } \\
\text { corresponde con los datos de la } \\
\text { RSN (UCR - ICE), ya que en esta } \\
\text { área se registraron valores de pH } \\
\text { entre } 2,68 \text { y 4,84. Para el caso de } \\
\text { La Pastora y El Tapojo, la } \\
\text { población participante manifestó } \\
\text { que no existe afectación por lluvia } \\
\text { ácida; sin embargo, para el caso } \\
\text { de El Tapojo se registró una } \\
\text { afectación fuerte y para el caso de } \\
\text { La Pastora una afectación leve. }\end{array}$ \\
\hline
\end{tabular}

Tabla 4. Resumen comparativo entre la percepción del grupo focal y la información científica sobre la lluvia ácida. Fuente: Propia, a partir de grupo focal (2017) y RSN (UCR-ICE) (2013).

\section{Percepción de riesgo por lahares}

En cuanto al riesgo asociado a los lahares la población identificó, según su percepción, que por el río Aquiares podrían viajar lahares, que eventualmente generarían afectación en el puente localizado sobre la Ruta Nacional 230 (Figura 7), que comunica La Pastora con Santa Cruz y Turrialba centro. Por tanto, es un elemento expuesto a ser afectado, además, representa para las comunidades una ruta de evacuación en caso de emergencia. Sin embargo, este riesgo fue calificado bajo, ya que el grupo focal siente que las lluvias características del área son un factor que ha ayudado a lavar el material volcánico, como la ceniza, que se acumula en la parte alta del volcán y esto ha evitado la formación de lahares de importante magnitud. 
Aunque se indicó que un posible lahar puede viajar por el río Aquiares y afectar el puente sobre la Ruta Nacional 230, los participantes del grupo focal mencionaron un evento de lahar que se dio el 4 de noviembre de 2014, el cual viajó por la quebrada Paredes y pasó cerca de la vivienda propiedad de Cristy Vander Laat, sin embargo, no se presentaron daños. Para este evento Lanamme - UCR (2015), indicó que el lahar se dio a consecuencia de los depósitos de ceniza en la cima del volcán y que se disparó por las constantes precipitaciones.

Asimismo, Ruiz et al (2015) realizaron una modelación de lahares generados por el volcán Turrialba y su posible afectación a un sector de la red vial nacional. Determinaron que, con una modelación de cinco, tres y dos millones de $\mathrm{m}^{3}$, podrían darse lahares que viajarían eventualmente por los cauces de ríos como Colorado, Turrialba, Pacayas, Birrís, Ortiga, Aquiares y Coliblanco, donde se verían afectados los puentes de las rutas 10, 230 y 415, sin embargo, las condiciones que se requieren para que se den lahares con un volumen total de 10 millones de $\mathrm{m}^{3}$ son bastante particulares. Por lo que se modeló un lahar más pequeño (con mayor posibilidad de ocurrir), de tan solo dos millones de $\mathrm{m}^{3} \mathrm{y}$ disparado desde las zonas de mayor acumulación de ceniza. Incluso Soto (2012) señala que existen registros del paso de lahares por el río Aquiares, que al parecer pueden corresponder con la erupción de 1864 - 1866 y que se pueden observar como parches a lo largo del río de menos de 2 m de espesor.
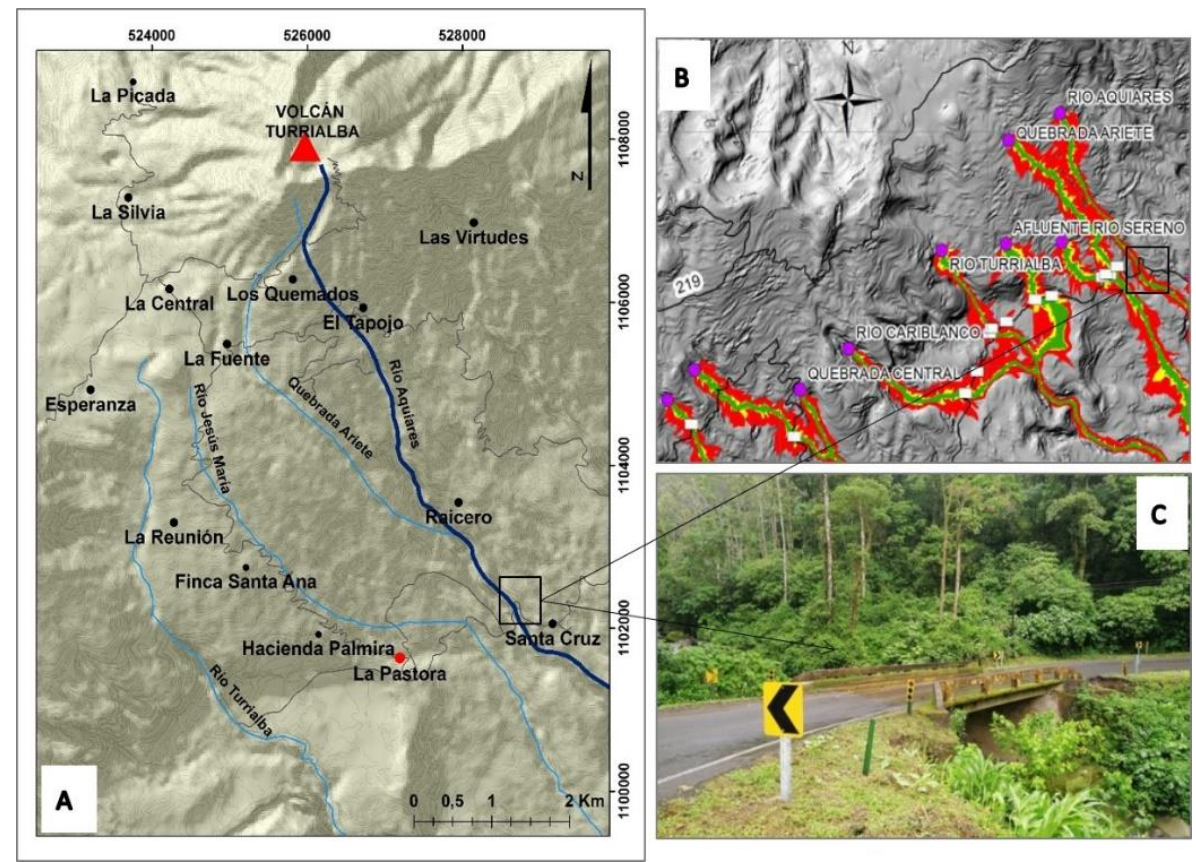

Figura 7. A). Percepción de riesgo por lahar por parte del grupo focal, donde la población señala posible afectación del puente sobre la ruta nacional 230. B). Modelación de lahares de 2 millones de $\mathrm{m}^{3}$ en el sector sureste del volcán Turrialba, con $95 \%$ de confiablidad, realizada por Ruíz et al. (2015), donde se aprecia el paso de lahares por el río Aquiares y que en los tres 
escenarios (peor, promedio y conservador) afectaría el puente sobre la ruta nacional 230. C). Puente sobre el río Aquiares en la Ruta Nacional 230. Fuente: Elaboración propia a partir de Ruíz et al., (2015), trabajo del grupo focal y trabajo de campo.

Los resultados arrojados por la investigación de Ruíz et al (2015), coinciden con la percepción del grupo focal, quienes señalaron el río Aquiares como el afluente por donde viajaría un posible lahar, que eventualmente afectaría el puente sobre la ruta nacional 230 (Tabla 5).

\begin{tabular}{|lllll|}
\hline \multicolumn{2}{|c}{ Percepción del grupo focal } & \multicolumn{2}{c}{ Información científica } & \multicolumn{2}{c|}{ Análisis comparativo } \\
\hline Según la percepción de la & Según los escenarios generados & Según el análisis realizado, la \\
población, existe un riesgo por & por Lanamme - UCR $(2015)$, se & percepción de la población \\
lahares, los cuales podrían viajar & determinó que, con una & coincide con el estudio de & de \\
por el río Aquiares e impactar el & modelación de cinco, tres y dos & Lanamme - UCR (2015), ya que \\
puente sobre la ruta nacional 230, & millones de $\mathrm{m}^{3}$, podrían darse & identificaron que existe un riesgo \\
la cual es de importancia para las & lahares que viajarían por el cauce & de afectación sobre el puente en la \\
comunidades La Pastora y El & del río Aquiares, donde se vería & ruta nacional 230, debido a \\
Tapojo en caso de emergencia, ya & afectado únicamente el puente de & lahares que podrían viajar por el \\
que la misma representa una & la ruta 230. & río Aquiares, tal como lo señala la \\
posible ruta de evacuación. & & investigación de Lanamme - UCR \\
\end{tabular}

Tabla 5. Resumen comparativo entre la percepción de la población y la información científica sobre lahares. Fuente: Elaboración propia a partir grupo focal (2017) y Ruíz et al., (2015).

\section{Percepción de riesgo por sismos}

En el macizo del Turrialba existen varias fallas, de las cuales, en el sector de la cima, sobresalen las fallas Ariete y Elia, definidas así por Soto (1998), mientras que en el sector sur se presenta la prolongación de la falla Aguacaliente-Navarro, que corta el flanco sur del macizo. Soto (2012) señala que, en el caso de sismos originados en estas fallas, se podrían tener rupturas del orden de 4 - $12 \mathrm{~km}$ de longitud que, de acuerdo con lo calculado, se obtendrían magnitudes máximas muy probables de $\mathrm{M}_{\mathrm{W}} 6,1$ - 6,2; probable $\mathrm{M}_{\mathrm{w}}$ 6,2 - 6,3 y poco probable $\mathrm{M}_{\mathrm{W}}$ 6,3 - 6,5. Estos sismos afectarían severamente sitios como Finca Central, lecherías vecinas y las áreas periféricas del sur y sureste del Irazú, así como el sur y sureste del Turrialba, como, por ejemplo, Pastora, Santa Cruz, Capellades, Pacayas, San Juan de Chicuá y alrededores (Soto, 2012). Por tanto, los sismos representan una amenaza de importancia para el área de estudio, ya que las fallas Ariete, Elia y Aguacaliente - Navarro, podrían generar magnitudes sísmicas entre los Mw 6,1 y 6,5. 
Estos datos coinciden con la percepción de los participantes del grupo focal, ya que manifestaron que los sismos representan un riesgo alto para La Pastora y El Tapojo, siendo las viviendas y puentes los elementos que ellos consideran se podrían ver afectados por la sismicidad (Tabla 6). Esta percepción se vio apoyada por el sismo acontecido el 30 de noviembre del 2016, a las 18:25 hora local, cuya magnitud fue de Mw 5,4 y se localizó $4.4 \mathrm{~km}$ al noroeste de Capellades de Alvarado. Resulta importante destacar que, en el área de estudio, la intensidad sísmica fue de VII (escala de Mercalli Modificada), por tanto, el sismo se sintió muy fuerte y provocó la caída de objetos en viviendas (Linkimer y Soto (2016; Linkimer et al, 2018).

Otro aspecto importante que resaltar es que el grupo focal identificó algunas estructuras presentes en el área de estudio, correspondientes a falla Ariete y falla Liebres, asimismo mencionaron la falla Alto Grande, el cerro Alto Grande y el anfiteatro avalancha del río Toro Amarillo (Tabla 6). Esto fue constatado con información geológica y geomorfológica (Figura 8), cuyo análisis arrojó que la población identificó correctamente dichas estructuras, las cuales han sido objeto de estudio en las investigaciones de Soto (1988), Montero y Alvarado (1995), Linkimer (2003) y Linkimer et al. (2018). 

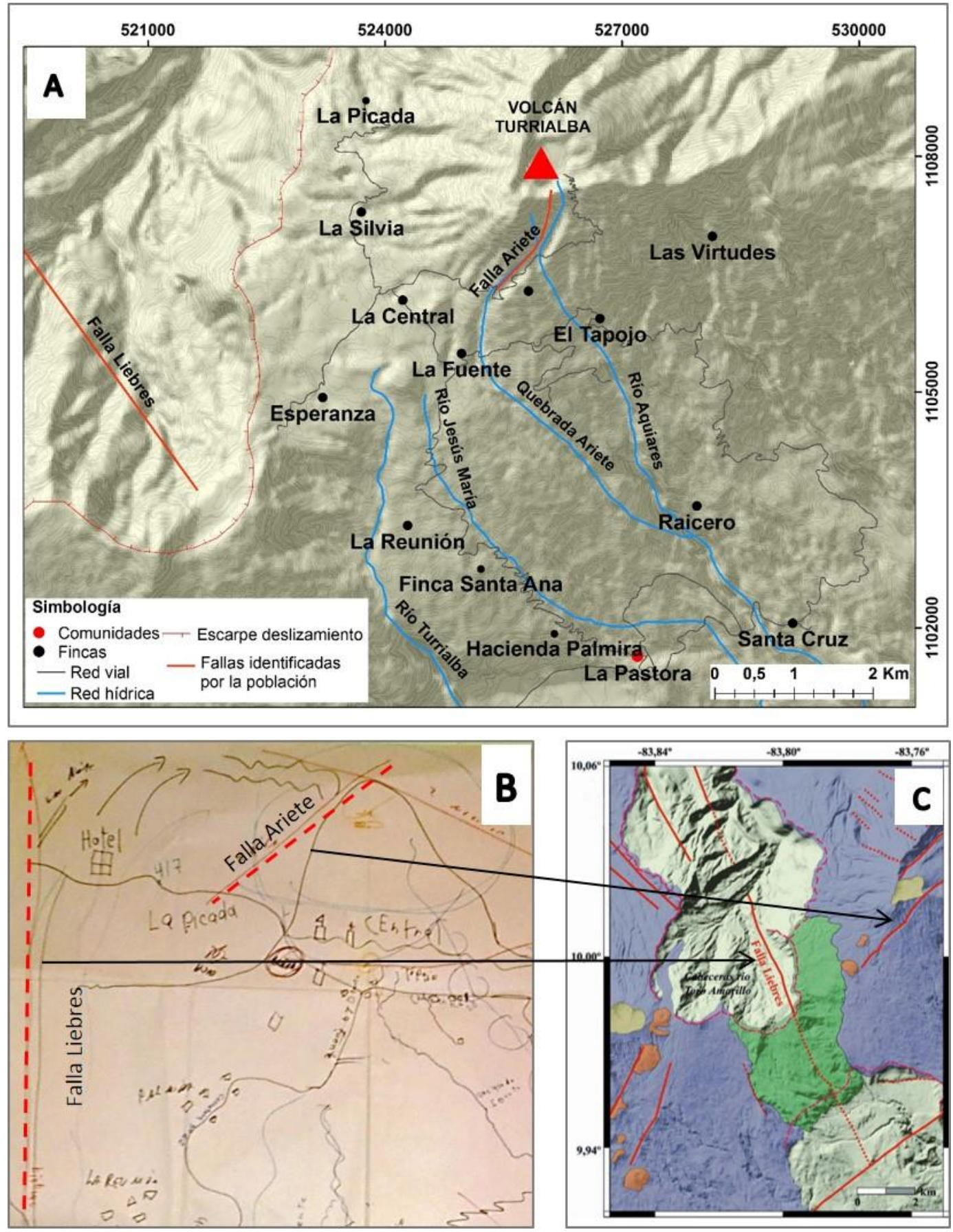

Figura 8. A). Falla Ariete y falla Liebres identificadas por el grupo focal en el mapa de riesgo asociado a eventos volcánicos para las comunidades La Pastora y El Tapojo, lo cual coincide con lo expuesto por Linkimer et al. (2018). B). Identificación de las fallas Ariete y Liebres en el mapa comunal de percepción de riesgo asociado a eventos volcánicos C). Identificación de las fallas Ariete y Liebres, así como, así como anfiteatro de deslizamiento del río Toro Amarillo, según investigación de Linkimer et al. (2018). Fuente: Elaboración propia a partir grupo focal (2017) y Linkimer et al. (2018).

Una de las razones por las cuales la población participante identificó la falla Alto Grande se debe a la geomorfología del sitio, ya que al oeste del volcán Turrialba se aprecian "un bloque o levantamiento de terreno" y, por el otro lado, un deslizamiento o "anfiteatro avalancha del río Toro Amarillo". Cabe destacar que esta falla fue relacionada con el sismo del 30 de noviembre de 2016, que generó 
deslizamientos en el área de estudio, dentro de los que destacan los del cerro Alto Grande. Desde La Silvia se observa el "bloque", el cual corresponde al cerro Alto Grande (Figura 9).

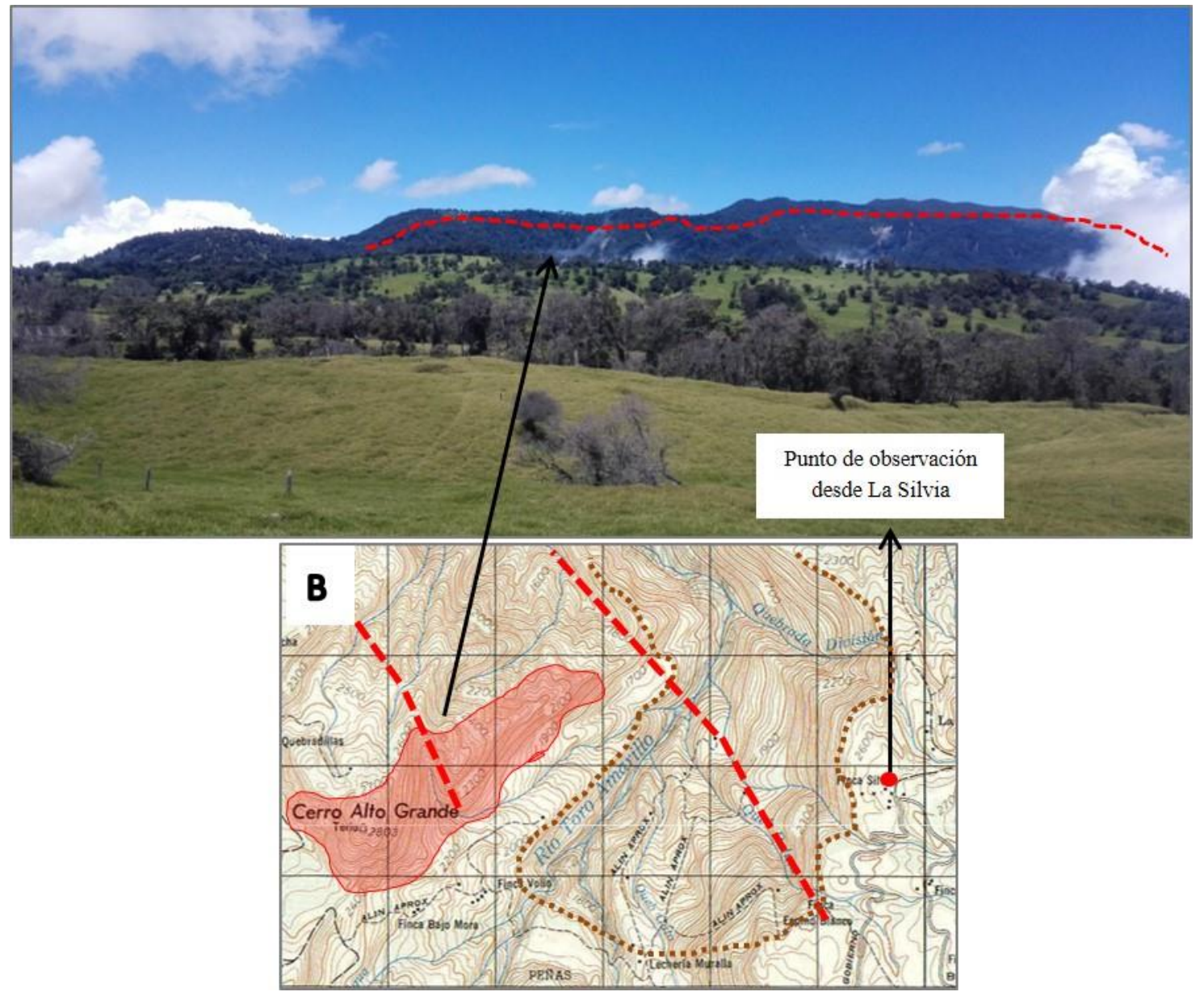

Figura 9. A). Vista panorámica, desde La Silvia, de la estructura percibida por la población como un "levantamiento de terreno", correspondiente al cerro Alto Grande y asociada a la falla del mismo nombre, la cual, según el grupo focal generó el sismo del 30 de noviembre de 2016 y provocó deslizamientos. B). Fuente: Propia, a partir de trabajo de campo (2017) y hoja topográfica Carrillo a escala 1:50 000. Cerro Alto Grande identificado y delimitado en la hoja topográfica Carrillo a escala 1:50 000, el cual se puede observar desde La Silvia.

Para el caso del "anfiteatro de avalancha del río Toro Amarillo", en los flancos del volcán Turrialba se han identificado varias avalanchas (debris avalanche). Para ello, el estudio de Alvarado et al. (2004), caracteriza algunas de estas estructuras conocidas como avalancha de Angostura, avalancha de Bajos y avalancha de Santa Rosa. Dichas unidades geomorfológicas, al ser propias de la configuración espacial del área de estudio, son perceptibles por los pobladores como, por ejemplo, la corona de deslizamiento ubicada en el río Toro Amarillo, la cual es identificada por la población y se le relaciona con el paso de la falla Alto Grande. El grupo focal identificó, además, otra geoforma, llamada popularmente "Altiplano La Pastora", que divide a la comunidad en una zona alta y una zona baja, y que, según los participantes, 
se puede apreciar claramente cerca de La Reunión. Se determinó que la zona señalada por el grupo focal como la parte baja de la comunidad, corresponde al anfiteatro de la avalancha de Coliblanco (Figura 10).
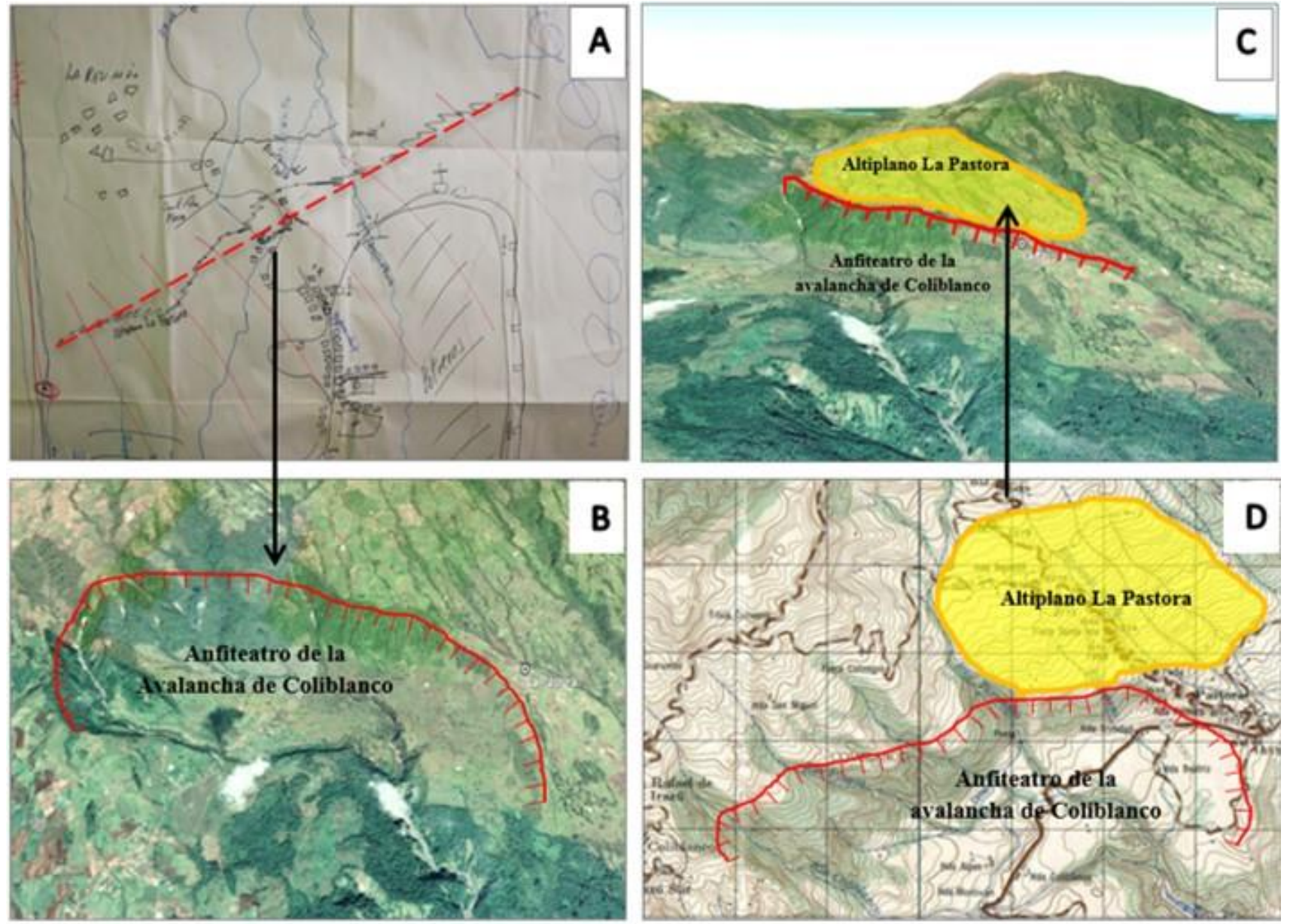

Figura 10. A). Área delimitada por el grupo focal como "altiplano La Pastora", el cual, según los pobladores del área de estudio divide a la comunidad en una zona alta y una zona baja. B). Imagen de Google Earth, donde se observa de manera oblicua el "anfiteatro de la avalancha de Coliblanco" cerca de La Reunión, lo cual coincide con la delimitación realizada por el grupo focal C). Vista oblicua obtenida de Google Earth, donde se muestra la delimitación de anfiteatro de la avalancha de Coliblanco, tal como lo plantean Alvarado et al. (2004) y el área del altiplano La Pastora. D) Delimitación del anfiteatro de la avalancha de Coliblanco y del Altiplano La Pastora en la hoja topográfica Istarú, escala 1:50 000, donde se pueden apreciar de manera clara, por las curvas de nivel, dichas estructuras. Fuente: Propia, a partir de grupo focal (2017) y hoja topográfica Carrillo a escala 1:50 000.

Esta geoforma se ubica justo en la divisoria de los volcanes Irazú y Turrialba, la cual es drenada por el río Turrialba. Dicha depresión tiene una forma en herradura irregular (área oblonga de unos 5 x 2,5 $\mathrm{km}$ ), cuyo piso posee una morfología irregular y una altura aproximada de $1580 \mathrm{~m}$ s.n.m. Mediante la realización de perfiles topográficos paralelos, se estimó un volumen de $2 \mathrm{~km}^{3}$ de material deslizado (Alvarado et al., 2004).

Percepción del grupo focal Información científica

Análisis comparativo 


\begin{tabular}{|c|c|c|}
\hline $\begin{array}{l}\text { La población participante } \\
\text { manifestó que existe un alto } \\
\text { riesgo sísmico, ya que } \\
\text { señalaron la existencia de } \\
\text { fallas, tales como Ariete, Alto } \\
\text { Grande y Liebres. Además, } \\
\text { recordaron sismos históricos } \\
\text { que generaron daños en el } \\
\text { área de estudio, por ejemplo, } \\
\text { el sismo de Capellades del } 30 \\
\text { de noviembre de } 2016 . \\
\text { Asimismo, identificaron otras } \\
\text { estructuras importantes en su } \\
\text { comunidad, tal como el } \\
\text { "altiplano La Pastora" y el } \\
\text { "anfiteatro de avalancha del } \\
\text { río Toro Amarillo", este } \\
\text { último asociado a la falla Alto } \\
\text { Grande. }\end{array}$ & $\begin{array}{l}\text { De acuerdo con la información } \\
\text { científica consultada, se } \\
\text { determinó que en el área de } \\
\text { estudio existen fallas como } \\
\text { Ariete, Elia, Alto Grande, } \\
\text { Liebres y Aguacaliente - } \\
\text { Navarro, que podrían generar } \\
\text { magnitudes sísmicas entre los } \\
\text { Mw 6,1 y 6,5. Asimismo, se } \\
\text { identificó que existen en el área } \\
\text { de estudio estructuras asociadas } \\
\text { a deslizamientos, tales como el } \\
\text { anfiteatro de avalancha de } \\
\text { Coliblanco y el "anfiteatro de } \\
\text { avalancha del río Toro } \\
\text { Amarillo". }\end{array}$ & $\begin{array}{l}\text { La población señalo que existe un alto } \\
\text { riesgo sísmico en el área de estudio, lo } \\
\text { cual coincide con la información } \\
\text { científica consultada, ya que fallas como } \\
\text { Ariete, Elia, Alto Grande, Liebres y } \\
\text { Aguacaliente - Navarro, podrían } \\
\text { generar magnitudes sísmicas entre los } \\
\text { Mw } 6,1 \text { y } 6,5 \text {. Se rescata, además, que } \\
\text { la población demarcó, según su } \\
\text { percepción, las fallas Ariete, Alto } \\
\text { Grande y Liebres. Asimismo, lo que } \\
\text { identificaron como el "altiplano La } \\
\text { Pastora", corresponde al anfiteatro de } \\
\text { avalancha de Coliblanco, datos que } \\
\text { indican que existe un conocimiento del } \\
\text { territorio por parte de los pobladores. }\end{array}$ \\
\hline
\end{tabular}

Tabla 6. Resumen comparativo entre la percepción del grupo focal y la información científica sobre sismicidad. Fuente: Elaboración propia a partir grupo focal (2017), Soto (1988), Montero y Alvarado (1995), Linkimer (2003) y Linkimer et al. (2018)

En relación con otros peligros establecidos en la metodología, tales como los deslizamientos, las coladas de lava y los flujos piroclásticos, el grupo focal manifestó no sentirse expuesta a ninguna. Sin embargo, para el caso de las coladas de lava, sí señalaron que la falla Ariete puede ser un punto importante de salida de lava, específicamente en un punto del camino que comunica con El Tapojo, ya que en este sector dicha falla ha presentado salida de gases, asociado a un intenso calor, tal como lo indicaron algunos de los participantes que han visitado el área.

De acuerdo con la información científica consultada (p.ej., Soto, 2012), se determinó que sí existe un potencial para la generación de deslizamientos y debris avalanches, asociados a la caída gravitacional de un sector del edificio volcánico, asimismo podrían ocurrir flujos piroclásticos que se podrían extender más de $10 \mathrm{~km}$ desde la cima del Turrialba, pero la mayoría se restringirían a unos pocos kilómetros de radio, tal como lo evidencia el registro geológico. Por último, las coladas de lava procedentes de la cúspide podrían alcanzar hasta cinco km de longitud, mientras que los flujos lávicos eruptados en fracturas en los flancos llegarían hasta ocho km del centro de emisión, aunque excepcionalmente han llegado a $20 \mathrm{~km}$ medidos desde la cima. 
Sumado a los peligros anteriormente mencionados, la población identificó elementos que podrían verse afectados por la actividad volcánica (cultivos, ganado, pastos, viviendas o puentes). Constituyéndose así riesgos, a los cuales el grupo focal le dio un valor correspondiente a alto, medio y bajo, según su percepción (Tabla 7).

\begin{tabular}{|ccc|}
\hline Peligro & Elementos expuestos & $\begin{array}{c}\text { Nivel de riesgo según } \\
\text { percepción }\end{array}$ \\
\hline Ceniza & $\begin{array}{c}\text { Cultivos, pastos, ganado, } \\
\text { viviendas y población }\end{array}$ & Alto \\
\hline Coladas de lava & Caminos & Bajo \\
\hline Gases & Población & Alto \\
\hline Lahares & Puentes & Medio \\
\hline Lluvia ácida & Cultivos, pastos y ganado & Bajo \\
\hline Sismos & Viviendas y puentes & Alto \\
\hline
\end{tabular}

Tabla 7. Valoración de riesgos asociados a la actividad del volcán Turrialba según percepción del grupo Focal durante el 2017. Fuente: Elaboración propia a partir grupo focal (2017).

Asimismo, para cada uno de los riesgos identificados, el grupo focal elaboró una síntesis de análisis (Tabla 8) donde se incluyó el tipo de peligro, impacto esperado, medidas de prevención o mitigación y actores responsables

\begin{tabular}{|c|c|c|c|c|}
\hline Peligro & & Impacto esperado & $\begin{array}{l}\text { Medidas de prevención o } \\
\text { mitigación }\end{array}$ & Actores responsables \\
\hline \multirow[t]{2}{*}{$\begin{array}{l}\text { Caída } \\
\text { ceniza }\end{array}$} & de & $\begin{array}{ll}\text { - } & \text { Quema de pastos y cultivos } \\
\text { - } & \text { Daños en el ganado } \\
\text { - } & \text { Afectación económica para } \\
\text { los productores } \\
\text { agropecuarios } \\
\text { - Emigración de la población } \\
\text { de las fincas cercanas al } \\
\text { volcán }\end{array}$ & $\begin{array}{ll}\text { - } & \text { Implementar } \\
\text { de reserva). } \\
\text { - } \\
\text { Invernaderos para el } \\
\text { ganado. } \\
\text { - Que los productores } \\
\text { cuenten con seguros para } \\
\text { disminuir las pérdidas. }\end{array}$ & $\begin{array}{ll}\text { - } & \text { Productores locales } \\
\text { - } & \text { MAG - SENASA } \\
\text { - } & \text { Aseguradoras }\end{array}$ \\
\hline & & $\begin{array}{ll}\text { - } & \text { Corrosión en techos } \\
\text { - } & \text { Enfermedades respiratorias y } \\
& \text { alergias en la población }\end{array}$ & $\begin{array}{ll}\text { - } & \text { Seguros para viviendas } \\
\text { - } & \text { Utilizar cubre bocas } \\
\text { - } & \text { Planes familiares de } \\
& \text { prevención } \\
\text { - } & \text { Barrer los techos }\end{array}$ & $\begin{array}{l}\text { - Cada unidad familiar en } \\
\text { coordinación con el CCE- } \\
\text { La Pastora. }\end{array}$ \\
\hline Gases & & $\begin{array}{l}\text { - } \begin{array}{l}\text { Enfermedades pulmonares y } \\
\text { alergias en la población, } \\
\text { principalmente niños y } \\
\text { adultos mayores }\end{array}\end{array}$ & $\begin{array}{ll}\text { - } & \text { Planes familiares de } \\
& \text { prevención } \\
\text { - } & \text { Uso de mascarillas }\end{array}$ & $\begin{array}{l}\text { - Cada unidad familiar en } \\
\text { coordinación con el CCE- } \\
\text { La Pastora. }\end{array}$ \\
\hline
\end{tabular}




\begin{tabular}{|c|c|c|c|}
\hline Sismos & 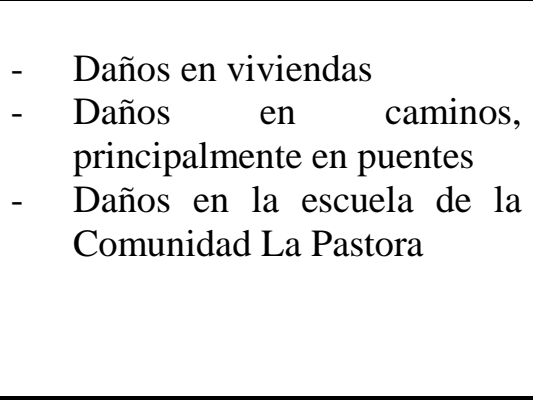 & $\begin{array}{lll}\text { - } & \begin{array}{l}\text { Estudios científicos } \\
\text { fallas cercanas y }\end{array} \\
\text { potencial sísmico. } & \\
\text { - } & \text { Planes Familiares de } \\
& \text { Prevención } \\
\text { - } & \text { Seguros para viviendas }\end{array}$ & $\begin{array}{ll}\text { - } & \text { Institutos de } \\
& \text { investigación } \\
& \text { (OVSICORI-UNA, RSN } \\
& \text { (UCR-ICE)) } \\
- & \text { CNE } \\
- & \text { Aseguradoras } \\
-\quad & \text { Cada unidad familiar en } \\
& \text { coordinación con el CCE- } \\
& \text { La Pastora. } \\
\end{array}$ \\
\hline Lahares & $\begin{array}{l}\text { - Daños en puentes y casas } \\
\text { cercanas a orillas del río } \\
\text { Aquiares } \\
\text { Pequeños deslizamientos en } \\
\text { el cauce del río Aquiares. }\end{array}$ & 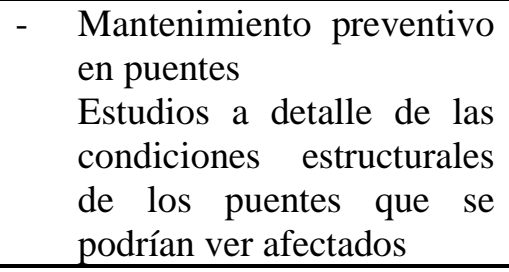 & $\begin{array}{ll}\text { - } & \text { Comisión Nacional de } \\
\text { Emergencias } \\
\text { - } & \text { Municipalidad } \\
\text { - } & \text { Ministerio de Obras } \\
\text { Públicas y Transporte } \\
\text { (MOPT) }\end{array}$ \\
\hline Lluvia ácida & $\begin{array}{l}\text { - Afectación en pastos en las } \\
\text { fincas que se encuentran } \\
\text { principalmente en el anillo } \\
1^{1} \text {. }\end{array}$ & $\begin{array}{l}\text { - } \begin{array}{l}\text { Implementar } \\
\text { de reserva) }\end{array} \\
\text { - } \begin{array}{l}\text { Invernaderos } \text { para el } \\
\text { ganado }\end{array} \\
\text { - } \text { Que los productores } \\
\text { cuenten con seguros para } \\
\text { disminuir las pérdidas }\end{array}$ & $\begin{array}{ll}- & \text { Productores locales } \\
\text { - } & \text { MAG - SENASA } \\
\text { - } & \text { Aseguradoras }\end{array}$ \\
\hline
\end{tabular}

Tabla 8. Análisis de riesgos asociados a la actividad del volcán Turrialba, según percepción. Fuente: Elaboración propia a partir grupo focal $(2017$

\section{CONCLUSIONES}

Existe una importante coincidencia entre los datos científicos de los peligros volcánicos del Turrialba y la percepción de la población, ya que señalan que la caída de ceniza, los gases, la sismicidad, la lluvia ácida y los lahares representan una amenaza para elementos que podrían verse afectados en la comunidad, principalmente las actividades agropecuarias, viviendas y puentes.

Los mapas de peligros volcánicos de Soto (2012), han facilitado a entidades, como el gobierno local y a la Agencia de Extensión Agropecuaria de Turrialba, la identificación de elementos expuestos (actividades agropecuarias, viviendas, escuelas, puentes y carreteras) a peligros como la caída de ceniza, la lluvia ácida, la caída de balística y lahares.

\footnotetext{
${ }^{1}$ El anillo uno corresponde a dos km alrededor del volcán, de acuerdo con lo establecido por la CNE corresponde a un área de alto riesgo.
} 
La actividad volcánica, principalmente la caída de ceniza, los gases y la lluvia ácida, ha generado que, en sectores cercanos al volcán, tales como La Picada, La Silvia y Los Quemados, se hayan dado procesos de emigración de la población, sin embargo, no se cuentan con datos sobre la cantidad de población que ha emigrado.

Octubre representa el mes más crítico para las comunidades ubicadas al sur del Turrialba, ya que una erupción de ceniza debido a la dirección de los vientos afecta de manera directa comunidades como Pastora o Tapojo, tal como lo acontecido con las erupciones de1 29 de octubre de 2014, del 16 al 31 de octubre de 2015 o del 13 y 14 de octubre de 2016.

Conocer la percepción del riesgo, en este caso asociado a los peligros volcánicos, es un factor que contribuye a la formulación de planes de gestión de riesgos o planes de emergencias que estén elaborados acorde a la realidad de las comunidades, ya que una comunidad que conoce e identifica los peligros a los que están expuestos, puede contribuir de manera activa a la formulación de lineamientos para la prevención y repuesta ante actividad volcánica. En este caso se evidencia que la población propuso medidas de prevención o mitigación para cada riesgo identificado, los cuales se pueden incorporar en un plan comunal de emergencias en el área de estudio.

\section{AGRADECIMIENTOS}

Se agradece a los líderes comunales de La Pastora y El Tapojo: Iracema Zuñiga, Hatzel Zuñiga, Lilliam Serrano, Auxiliadora Chaves, Rolando Pacehco y Miriam Corrales por aportar su conocimiento en esta investigación, a la Universidad Nacional (UNA) por medio del Observatorio Sismológico y Vulcanológico de Costa Rica (OVSICORI) que contribuyó en la logística para el trabajo comunal y en las tareas de campo que se realizaron durante esta investigación.

\section{REFERENCIAS}

Abarca, T., y Alvarado G. (2017). Pérdidas económicas en valor presente al año 2016 causadas por el vulcanismo en Costa Rica entre 1953 y 2016. Revista Geológica de América Central, 56: 37-50. 
Agencia de Extensión Agropecuaria de Turrialba. (2014). Censo de cultivos horticolas y observación de posibles daños por volcán Turrialba. Cartago: MAG. Informe interno.

Agencia de Extensión Agropecuaria de Turrialba. (2015). Evaluación de daños a cultivos por erupciones del volcán Turrialba del 24 de octubre del 2015. Cartago: MAG. Informe interno.

Agencia de Extensión Agropecuaria de Turrialba. (2016). Distribución de insumos y materiales para la atención de la emergencia volcán Turrialba: informe de situación erupción volcán Turrialba. Cartago: MAG. Informe interno.

Agencia de Extensión Agropecuaria de Turrialba. (2017). Evaluación de daños a cultivos por erupciones del volcán Turrialba del 26 al 30 de marzo del 2017. Cartago: MAG. Informe interno.

Alvarado, G.E., Vega. E., Chaves, J. y Vásquez, M. (2004). Los grandes deslizamientos (volcánicos y no volcánicos) de tipo debris avalanche en Costa Rica. Revista Geológica de América Central, 30: 83-99.

Alvarado, G., Brenes-André, J., Barrantes, M., Vega, E., De Moor, J., Avard, G., Dellino, P., Mele, D., Devitre, C., Di Piazza, A., Rizzo, A. y Carapezza, M. (2016). La actividad explosiva del volcán Turrialba (Costa Rica) en el periodo 2010 2016. Revista Geológica de América Central, 55: 7-60.

Arguedas, C. (4 de noviembre de 2014). 13 pueblos sufren por erupciones del volcán Turrialba. Periódico La Nación. Recuperado de: http://www.nacion.com/sucesos/desastres/pueblos-sufren-erupciones- Turrialba_0_1449255092.html

Campos, D. y Alvarado, G.E. (2018). Análisis de la distribución espaciotemporal de la caída de cenizas del volcán Turrialba (2010 - 2018), Costa Rica: isofrecuencia, volumen y afectación. Revista Geológica de América Central, 59: 23-39.

Duarte, E. (2015). Impacto ambiental y socioeconómico del volcán Turrialba según monitoreo realizado entre 1980 y 2015. Revista Ambientico, 254: 4 -16.

Hamui, A., y Varela, M. (2013). La técnica de grupos focales. Investigación en educación médica. 2: 55-60. Recuperado de: http://riem.facmed.unam.mx/sites/all/archivos/V2Num01/09_MI_HAMUI.PDF

Hilton, D.Ramírez, C., Mora, R. Fisher, Füri. E, Barry y Shaw, A. (2010). Monitoring of temporal and spatial variations in fumarole helium and carbon dioxide characteristics at Poás and Turrialba volcanoes, Costa Rica (2001- 2009). Geochemical Journal, 44: 431 - 440 .

Linkimer, L. (2003). Neotectónica del extremo oriental del cinturón deformado del centro de Costa Rica. (Tesis de pregrado). Universidad de Costa Rica, San José, Costa Rica.

Linkimer, L. Soto, G. (2016). Informe preliminar: El Sismo de Capellades del 30 de noviembre del 2016. Red Sismológica Nacional de la Universidad de Costa Rica. Recuperado de:

http://rsn.ucr.ac.cr/images/Noticias/2016_12/informe_sismo_capellades_2016.pdf

Linkimer, L., Arroyo, I., Soto, G., Porras, J., Araya, C., Mora, M., y Taylor, M. (2018). El sismo de Capellades del 2016 y su secuencia sísmica: Manifestación de fallamiento de rumbo en el arco volcánico de Costa Rica. Boletín de Geología, 40, 35 53. DOI: http://dx.doi.org/10.18273/revbol.v40n2-2018002

Martini, F. (2009). Proyecto: Efecto de las emisiones de gases volcánicos y acidificación del medio ambiente sobre la salud humana en las comunidades en los alrededores del Volcán Turrialba. Universidad Nacional, Heredia, Costa Rica.

Martini, F., Van Der Laat, R., del Potro, R., Brenes, J., Duarte, E. y Fernández, E., (2008). Unrest of Turrialba volcano (Costa Rica) after 143 years of quiescence: Geophysical, Geochemical and Geodetical data during ten years of monitoring. Asamblea General del IAVCEI "Understandig Volcanoes”. Reykjavík, Islandia. 
Ministerio de Agricultura y Ganadería. (2010). Plan de Acción Agropecuario para la Mitigación de la Actividad Freática en el Área de Influencia del Volcán Turrialba. San José: MAG. Informe interno.

Montero, W., y Alvarado, G. E. (1995). El terremoto de Patillos del 30 de diciembre de $1952(\mathrm{Ms}=5,9)$ y el contexto neotectónico de la región del volcán Irazú, Costa Rica. Revista Geológica de América Central, 18: 25-42.

Red Sismológica Nacional de la Universidad de Costa Rica. (2013). Lluvia ácida Turrialba 2007-2013. Informe interno. Recuperado de: http://rsn.ucr.ac.cr/documentos/informativos/lluvia-acida-turrialba

Ruíz, P. Vega, P. Barrantes, R. Loria, L. (2015). Modelación de lahares generados por el volcán Turrialba y su posible afectación a la red vial nacional. Recuperado de: http://www.lanamme.ucr.ac.cr//repositorio/handle/50625112500/42

Soto, G. (agosto de 1988). Estructuras volcano-tectónicas del Volcán Turrialba, Costa Rica, América Central. V Congreso Geológico Chileno, Santiago de Chile.

Soto, G. (2012). Preparación de mapas de peligros volcánicos y restricción de uso de la tierra en el volcán Turrialba. Mapa de peligros volcánicos del volcán Turrialba. Comisión Nacional de Riesgos y Prevención de Emergencias. Recuperado de: http://rsn.ucr.ac.cr/images/Noticias/2012_11/Informe_final_peligros_VTurrialba-Fundevi_a_CNE_2012.pdf

Tilling, R. (1989). Volcanic hazards. American Geophysical Union. United States.

Yglesias, M., y Chamizo, H. (2014). Susceptibilidad y síntomas respiratorios asociados a la exposición a dióxido de carbono y dióxido de azufre provenientes del volcán Turrialba, Costa Rica. Revista Población y Salud en Mesoamérica, $12: 1$ - 14. 